\title{
La historia clínica y el examen físico son útiles para identificar etiologias serias asociadas a la consulta en guardia por llanto
}

Clinical history and physical examination are helpful in identifying serious etiologies associated with the crying infant evaluated in the emergency department

Freedman S y col. Pediatrics 2009;123;841-848

\section{Objetivo}

Determinar la proporción de lactantes que consultan por llanto asociado a un diagnóstico etiológico serio (DES) en una central de emergencias y determinar el aporte de la historia y el examen físico (clínica) así como los estudios complementarios de laboratorio $(E C L)$ para determinar el diagnóstico.

\section{Diseño}

Estudio descriptivo retrospectivo.

\section{Lugar}

Hospital de nivel terciario en Toronto, Canadá

\section{Población}

Pacientes menores de 12 meses que consultaron a la central de emergencia por llanto entre enero y septiembre de 2005.

\section{Medición de resultados principales}

El resultado principal fue la proporción de lactantes con DES definidas por seis expertos como aquellas en las que se prevé una evolución desfavorable si no se realiza un rápido diagnóstico y tratamiento. El resultado secundario fue la proporción de lactantes con DES no sospechado por la clínica.

\section{Resultados}

Sobre un total de 37.549 visitas a la guardia, 238 consultaron por llanto (0,6\%). En 12 (5\%) lactantes se estableció un DES; en diez casos durante la consulta inicial y en dos, durante la semana posterior inmediata. La infección urinaria fue la causa más frecuente, presente en tres $(25 \%)$ de los pacientes. Los hallazgos positivos de la clínica sugirieron el diagnóstico final en el $66,4 \%$ de los casos. Fueron identificados siete lactantes con mala apariencia clínica, de los cuales cuatro $(57,1 \%)$ presentaron un DES. En total se realizaron $574 \mathrm{ECL}$, de los cuales $81(14,1 \%)$ resultaron positivos. Sin embargo, sólo en ocho $(1,4 \%)$ casos aportaron al diagnóstico final: seis $(2,5 \%)$ lactantes con hallazgos clínicos y dos $(0,8 \%)$ menores de cuatro meses con clínica normal y diagnóstico de infección del tracto urinario. En un $30,3 \%$ de los casos tanto la clínica como los ECL fueron negativos para realizar un diagnóstico.

\section{Conclusiones}

La clínica continúa siendo la herramienta diagnóstica más relevante en el diagnóstico del lactante con llanto, y debería guiar a la elección de los estudios complementarios. Los lactantes afebriles que consultan por llanto en los primeros meses de vida podrían ser evaluados mediante exámenes de orina.

Palabras claves: Llanto, emergencias, diagnóstico.

Keywords: crying, emergencias, diagnosis.

Fuentes de financiamiento: no reportada.

\section{Comentario}

A diferencia de otros temas como el manejo del cólico del lactante, existen pocos trabajos publicados sobre el abordaje clínico en la guardia del lactante que llora, por lo que celebramos la publicación de este estudio, que presenta un análisis interesante que coincide con nuestra experiencia, ratificando a la clínica como pilar fundamental para llegar a un diagnóstico adecuado en esta situación.

La impresión clínica parece ser valiosa para decidir estudiar al lactante, y en este caso, la mayoría de los ECL que aportaron a un diagnóstico fueron solicitados sobre la base a hallazgos clínicos. Queda a consideración el examen de orina y urocultivo en lactantes pequeños, aún en ausencia de fiebre sin foco. Entre sus limitaciones, mencionamos que se trata de un estudio retrospectivo. Los autores informan una frecuencia mayor de DES en lactantes mayores de cuatro meses, lo que podría explicarse por la mayor prevalencia de cólicos en lactantes de menor edad. Por otro lado, no describen las características del Ilanto, información que podría haber resultado interesante. Si bien se definieron los DES mediante un acuerdo entre expertos, consideramos que algunos de los incluidos pueden discutirse, como la fractura de clavícula, representada por dos los pacientes que integraron la muestra y que no pone en riesgo la vida del lactante. Por otro lado, otras etiologías no incluidas como otitis media o el reflujo gastro esofágico- podrían haber sido consideradas.

\section{Conclusiones del comentador}

El lactante que consulta a la guardia por llanto rara vez tiene una etiología seria. La historia y el examen físico minuciosos aportan generalmente la causa del llanto o guían la solicitud de estudios complementarios adecuados. Son pocos los estudios disponibles sobre este tema y seguramente la evidencia se robustecerá si se continúa investigando el mismo con mejores diseños metodológicos.

Julio Busaniche [ Servicio de Clínica Pediátrica del Hospital Italiano de Buenos Aires. julio.busaniche@ @ospitalitaliano.org.ar ]

Busaniche J. Causas de enfermedades graves en lactantes con llanto y métodos diagnósticos solicitados. Evid Act Pract Ambul. 12(4). 130. Oct-Dic. 2009. Comentado de: Freedman S y col. The crying infant: diagnostic testing and frequency of serious underlying disease. Pediatrics. 2009 Mar;123(3):841-8. PMID: 19255012. Disponible bajo suscripción: http://pediatrics.aappublications.org/cgi/content/abstract/123/3/841

Referencias

1. Poole SR. The infant with acute, unexplained, excessive crying. Pediatrics. 1991 Sep;88(3):450-5

2. Cohen-Silver J y col. Management of infantile colic: a review. Clin Pediatr (Phila) 2009 Jan;48(1):14-7. 